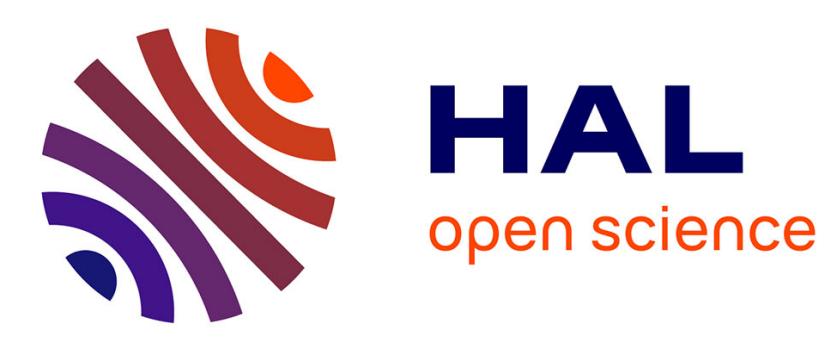

\title{
Micro EDM Milling with Low Energy Discharges and Thin Microtool
}

\author{
Rabah Dahmani, Yasmina Layouni, Vincent Semet, Michel Cabrera
}

\section{To cite this version:}

Rabah Dahmani, Yasmina Layouni, Vincent Semet, Michel Cabrera. Micro EDM Milling with Low Energy Discharges and Thin Microtool. 4M/ICOMM2015 Conference, Mar 2015, Milan, Italy. hal01306795

\section{HAL Id: hal-01306795 \\ https://hal.science/hal-01306795}

Submitted on 25 Apr 2016

HAL is a multi-disciplinary open access archive for the deposit and dissemination of scientific research documents, whether they are published or not. The documents may come from teaching and research institutions in France or abroad, or from public or private research centers.
L'archive ouverte pluridisciplinaire HAL, est destinée au dépôt et à la diffusion de documents scientifiques de niveau recherche, publiés ou non, émanant des établissements d'enseignement et de recherche français ou étrangers, des laboratoires publics ou privés. 


\title{
Micro EDM milling with low energy discharges and thin microtool
}

\author{
R. Dahmani, Y.Layouni, V. Semet, M. Cabrera
}

\author{
Université de Lyon, Institut des Nanotechnologies de Lyon (INL), UMR 5270 CNRS INSA ECL UCB CPE, \\ Bât. L. Brillouin, 43 Bd du 11 Nov. 1918, F69622 Villeurbanne, France \\ michel.cabrera@univ-lyon1.fr
}

\begin{abstract}
The aim of this paper is to report on micro EDM milling of stainless steel with ultrathin and high aspect ratio microtools and explore possibilities for machining with small discharges using a ballast resistor. Machining of channels is demonstrated with a $9 \mu \mathrm{m}$ tungsten microtool with $29 \mathrm{~nJ} /$ discharge without damaging the tool. Depending on the value of the ballast resistor $R_{b}$, the channel width is about 31-36 $\mu \mathrm{m}$ with aspect ratio of 1.4-1.8. The most significant result is that the relative tool wear ratio is below $0.01 \%$ when $\mathrm{Rb}$ is greater than $100 \Omega$. It allows machining at $50 \mathrm{~V}$ operating voltage with $1 \mathrm{nF}$ working capacitance without using the stray capacitance of the machine.
\end{abstract}

Keywords: Micro EDM; Micro EDM milling; Microtool; Tool wear; Stainless steel.

\section{Introduction}

Micro electrical discharge milling is a process of growing importance, which allows machining of complex parts made of electrically conductive material by controlling the three dimensional path of a thin cylindrical microtool [1]. Contrary to micromilling based on chips formation, micro EDM milling is a non-contact process so that ultrathin microtools can be in theory used. However, the process is still challenging as regards many aspects (discharge energy, vibrations,...) $[2,3]$. Therefore, the aim of this paper is to report on the machining with ultrathin and high aspect ratio microtools and on the use of small energy discharges.

\section{Experimental set up}

This work is based on the $2^{\text {nd }}$ generation micro EDM milling machine, which has been entirely developed in our laboratory. Among other features, the microtool manufacturing is made by electrochemistry. The machine has also a generator allowing generating low energy discharges.

The machine has basically two functions: - To etch cylindrical ultrathin microtools by electrochemical dissolution of tungsten rods in the microtool manufacturing station $(5 \mathrm{Mol} / \mathrm{L} \mathrm{NaOH})$.

- To machine parts by micro EDM milling with these tools in the micro EDM station.

The machine (Fig. 1) is equipped with translation stages with stepper motors (0.3125 $\mu \mathrm{m}$ microstep), which allow moving the two stations and the microtool respectively in the horizontal $X Y$ and vertical $Z$ directions. The gap between the tool and the part is adjusted with a piezoelectric actuator (90 $\mu \mathrm{m}$ range; $1.8 \mathrm{~nm}$ resolution) and the tool wear is compensated with a stick slip actuator. A side view camera, with a Navitar x12 zoom, allows viewing the tool (camera 1). A top view camera with a second Navitar x12 zoom allows viewing the part (camera 2). All components are installed on a vibration isolation workstation.

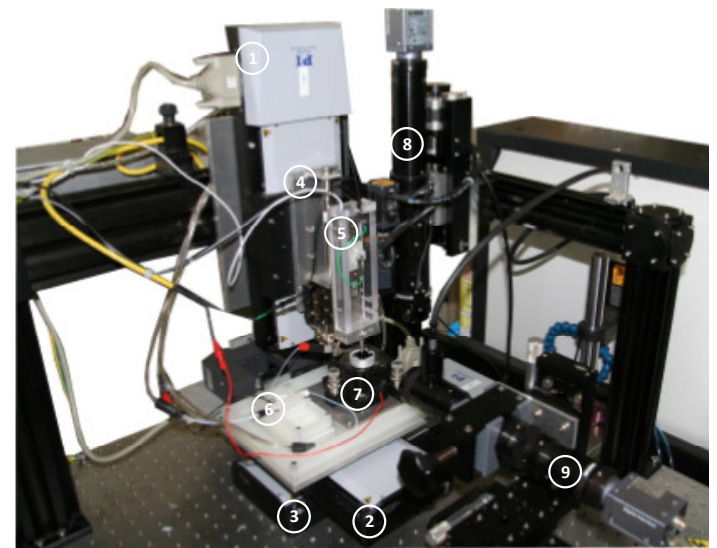

Fig. 1. $2^{\text {nd }}$ generation Micro EDM milling machine: (1) $Z$ translation stage; (2) $Y$ translation stage; (3) $X$ translation stage; (4) Piezoelectric actuator; (5) Stick slip actuator; (6) Microtool manufacturing station; (7) Micro EDM station; (8) Camera 2; (9) Camera 1.

The $1^{\text {st }}$ generation of micro EDM milling machine and the microtool manufacturing station have been already described [4-6]. Therefore, we shall report here only briefly on the new features of the $2^{\text {nd }}$ generation machine, which are mainly related to the electronics.

This one is based on a parallel architecture (Fig. 2) with 3 microcontrollers $(\mu \mathrm{C})$ in order to $(1)$ monitor the process, (2) detect events which may happen simultaneously and (3) trigger actions with a fast response time, such as:

- Movements of the microtool and of the part.

- Discharge generation (see RC generator below).

- Discharge characterization with the help of a series of voltage comparators [6].

- Detection of the contact between the tool and the part (see below).

- Retraction of the microtool in case of contact.

- Regulation of the gap with the piezoelectric actuator.

- Tool wear compensation with the stick slip actuator.

In this paper, we shall demonstrate machining with 
a $9 \mu \mathrm{m}$ diameter microtool. No spindle is used to rotate the tool. The first challenge is to avoid the destruction of the tool during a possible collision. The second challenge is to reduce the discharge energy in order to improve machining resolution.

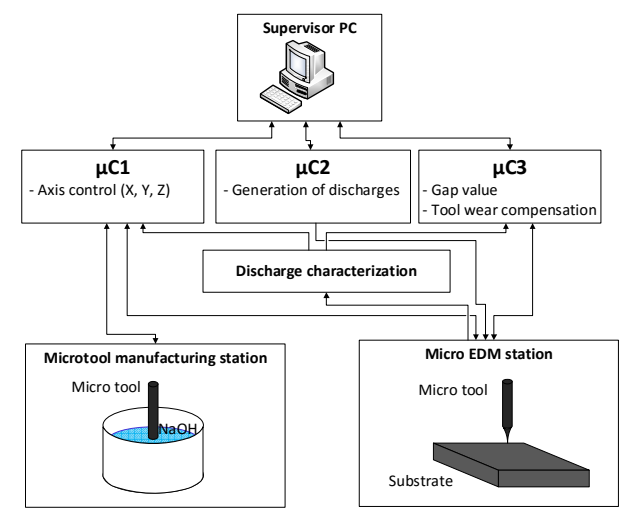

Fig. 2. Parallel architecture of the electronics of the machine.

In its simplest form, the generator of electrical discharges is of $\mathrm{RC}$ type with a resistor $\mathrm{R}_{\mathrm{c}}$ and a working capacitance $\mathrm{C}_{\mathrm{c}}$. In addition, a ballast resistor $\mathrm{R}_{\mathrm{b}}$ has been introduced in series with the microtool in order to reduce the energy of the discharges (Fig. 3). The part is at positive polarity.

A $200 \mathrm{MHz}$ bandwidth DPO 2024 Tektronix oscilloscope is used to record:

- The current flowing through the microtool with a $100 \mathrm{MHz}$ TCPA300 Tetktronix DC current probe.

- The voltage across the working capacitance $C_{C}$ with a $100 \mathrm{MHz}$ differential voltage P5205 Tektronix probe.

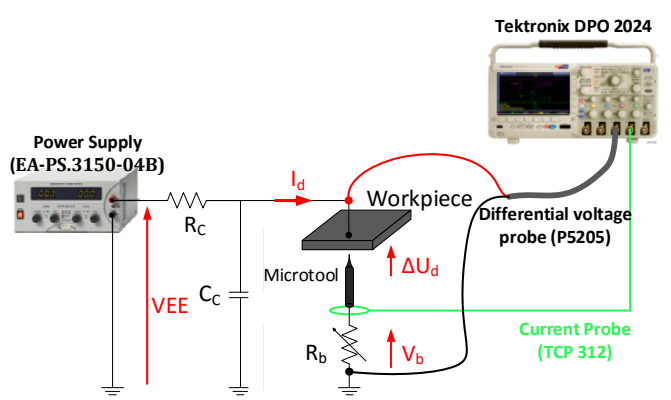

Fig. 3. $R_{C} C_{c}$ discharge generator with $R_{b}$ ballast resistor operating at VEE voltage.

\section{Machining of stainless steel}

\subsection{Electrochemical etching of the microtool}

The machine allows electrochemical etching of tungsten rods with $250 \mu \mathrm{m}$ initial diameter down to 4$10 \mu \mathrm{m}$ diameter with very high aspect ratio (see ref [46] for details, including repeatability of the tool realization). Fig. 4 shows a view of a tungsten microtool with $9 \mu \mathrm{m}$ average diameter (0.66 $\mu \mathrm{m}$ STD) along the $500 \mu \mathrm{m}$ working length as imaged with camera 1 and characterized with a Mitutoyo LSM-500S laser profilometer (working range: $5 \mu \mathrm{m}-2 \mathrm{~mm}$; precision: $10 \mathrm{~nm}$ ). The aspect ratio of the microtool is about 50 .

The microtool is used for machining stainless steel substrates in deionized water. To prepare the substrates, a sheet with mirror like aspect (ref 559-206 from Radiospares) is cut with plasma into $20 \times 20 \times 0.6 \mathrm{~mm}$ pieces. All substrates are polished.

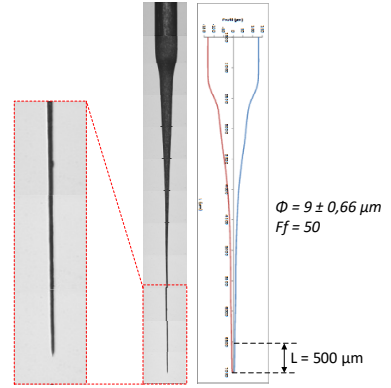

Fig. 4. Microtool with $9 \mu \mathrm{m}$ diameter and aspect ratio of 50 .

\subsection{Machine set up}

The initial gap between the microtool and the part is set up without deionized water (Fig. 5): the tool is slowly translated downward until electrical contact is reached and moved upward of $5 \mu \mathrm{m}$. Then a goniometer allows adjusting the gap during the lateral movement of the part so that it remains in the $5+/-1 \mu \mathrm{m}$ range for $500 \mu \mathrm{m} \mathrm{XY}$ translations (as checked with camera 1). Then deionized water is added and machining can be started.

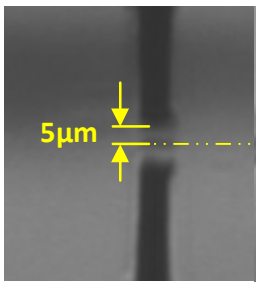

Fig. 5. Initial gap between the microtool and the part (direct image and image reflected by the substrate).

The channel shown in Fig. 6a is machined with the $500 \times 100 \mu \mathrm{m} \times Y$ rectangular tool path of Fig. 7 at $156 \mu \mathrm{m} / \mathrm{s}$ speed. The tool always moves down of one microstep $\mathrm{h}(0.3125 \mu \mathrm{m})$ when coming back at the same corner. Then the machining cycle is repeated again. A total of 160 layers is machined so that the theoretical height $\mathrm{H}_{\mathrm{c}}$ of the channel is $50 \mu \mathrm{m}$.

A voltage comparator allows comparing the voltage across $C_{C}$ with a threshold value (typically $0.5 \mathrm{~V})$. When the voltage is below this threshold, the tool is retracted and flushing is performed long enough in order to recover the gap isolation. Then the tool is moved down to its original position and machining is started again.

A series of channels have been machined at different values of $R_{b}$ (5 to $500 \Omega$ ) with $50 \mathrm{~V}$ VEE,

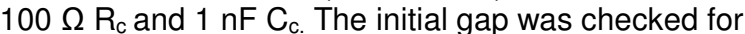
each channel. After each machining, the tool wear was measured with camera 1 . The parts were also molded with polydimethylsiloxane PDMS (Fig. 6b).

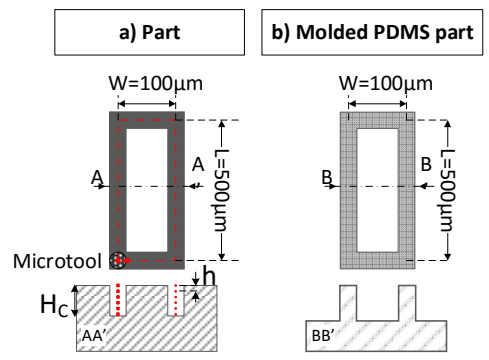

Fig. 6. (a) Dimensions of the machined part. (b) Molded part. 


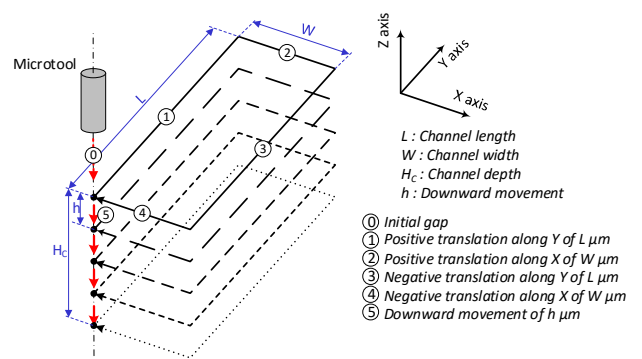

Fig. 7. Tool path for micro EDM milling.

\subsection{Characterization of discharge energy}

Fig. 8 shows typical waveforms of voltage across the capacitance $\mathrm{C}_{c}$ and current discharge at different $R_{b}$. The discharge energy is calculated by integrating the recorded voltage and current and subtracting the energy dissipated in $R_{b}$. Typical discharge energies vary from $4.1 \mu \mathrm{J}$ for $R_{b}=5 \Omega$ to $29 \mathrm{~nJ}$ for $R_{b}=500 \Omega$ (Fig. 9).

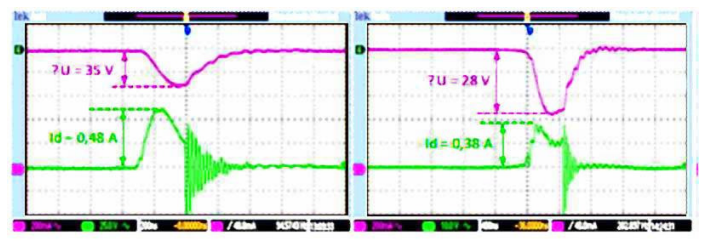

(1) $R_{b}=5 \Omega$

(2) $R_{b}=20 \Omega$

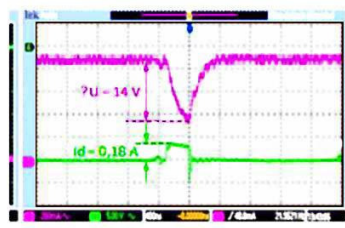

(3) $R_{b}=100 \Omega$

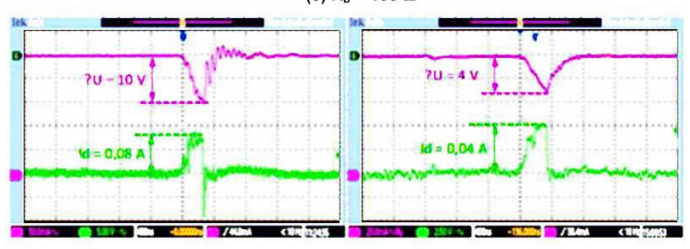

(4) $R_{b}=200 \Omega$

(5) $R_{b}=500 \Omega$

Fig. 8. Voltage and current during a discharge at $R_{b}=5,20$ 100,200 and $500 \Omega\left(\mathrm{VEE}=50 \mathrm{~V}, \mathrm{C}_{\mathrm{C}}=1 \mathrm{nF}, \mathrm{R}_{\mathrm{C}}=100 \Omega\right.$, initial gap $=5 \mu \mathrm{m})$.

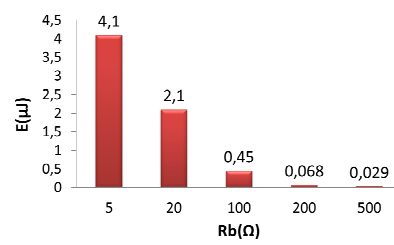

Fig. 9. Variation of the discharge energy with the value of the ballast resistor.

\subsection{Characterization of machined microchannels}

Fig. 10 shows top views of the machined channels recorded with camera 1 . The images tend to show that the higher the $R_{b}$, the sharper the channel edges. However, views with a scanning electron microscope (SEM) do not confirm this statement (Fig. 11).

$A$ regards the molded part, Fig. 12 is a side view with camera 1 and Fig. 13 is a top view with the SEM. They show similar surface roughness for all values of $R_{b}$.

Fig. 14 shows the depth $\mathrm{H}$ and width $\mathrm{W}$ of the molded channels at different $R_{b}$ as measured with the SEM and camera 1. As molding with PDMS is very precise [7], the geometrical measurements characterize mainly micro-EDM.

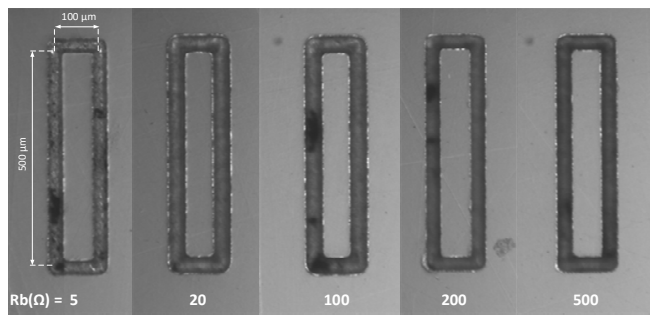

Fig. 10. Top views of the channels machined in stainless steel (camera 2).
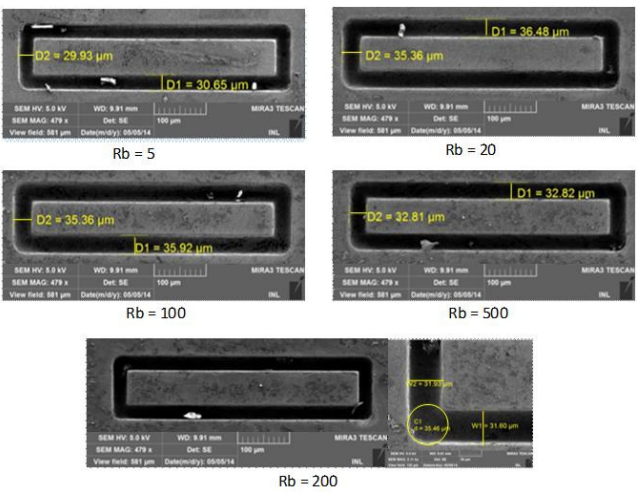

Fig. 11. Top view of the channels machined in stainless steel (SEM).

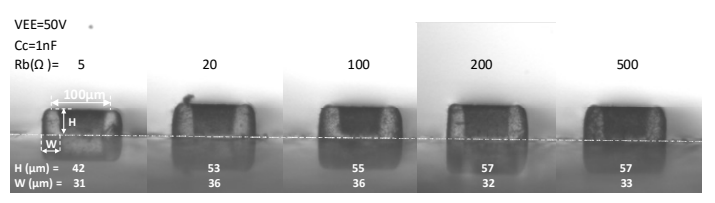

Fig. 12. Side view of the channels molded with PDMS (camera 1) with mirrored image.

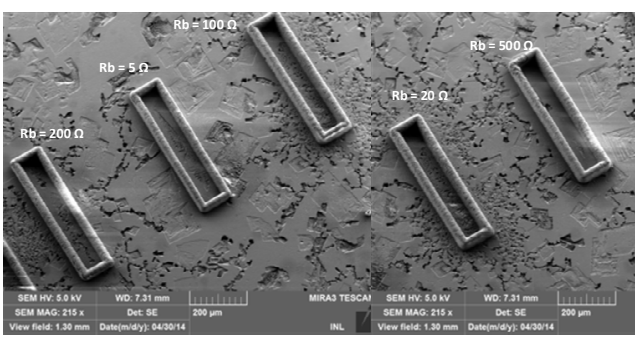

Fig. 13 Top view of the channels molded with PDMS (SEM).

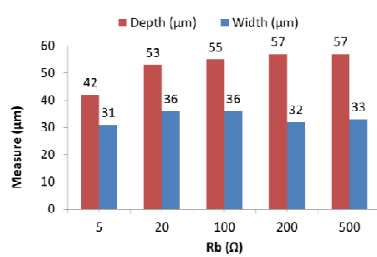

Fig. 14. Depth and width of the molded channels at different values of ballast resistor. 
So, thanks to the use of $R_{b}$, machining has been demonstrated with an energy as low as $29 \mathrm{~nJ} /$ discharge at $1 \mathrm{nF}$ capacitance and $50 \mathrm{~V}$ operating voltage. In the literature, the use of such small energy discharges has been rarely reported and is performed in general with the stray capacitance of the machine at low operating voltage $[2,3]$. This is a disadvantage since the performance of the machine is less predictable: the stray capacitance may vary from one machine to another and the operating voltage is close to the polarization voltage of the components and the electrical noise.

\subsection{Removal rate and tool wear}

The $\varnothing 9 \mu \mathrm{m}$ microtool is not damaged during the machining. This demonstrates that the electronics of the machine (Fig. 2) protects the microtool in an efficient manner.

Fig. 15 shows the final gap after the machining of every channel. The worn length of the tool is deduced by comparison with the initial gap (Fig. 5). This allows estimating (Table 1):

-The tool removal rate (TRR), which is the ratio of the worn volume of the tool with machining time.

-The material removal rate (MRR) which is the ratio of the volume removed from the part with machining time. -The relative tool wear RTW which is the ratio of TRR with MRR.

RTW decreases when $R_{b}$ increases. For $R_{b}$ greater than $100 \Omega$, RTW below $0.01 \%$ is obtained.

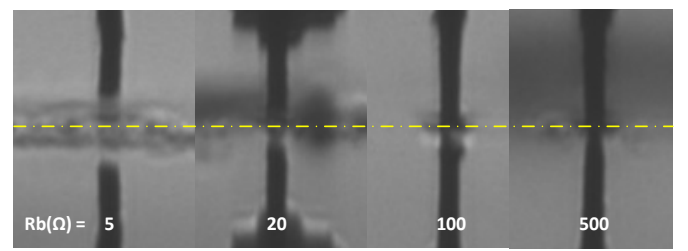

Fig. 15. Gap after the machining of the channels showing tool wear (direct image and image reflected by the substrate).

Table 1.

Material removal rate, tool removal rate, relative tool wear and energy / discharge at different values of ballast resistor.

\begin{tabular}{lllll}
\hline $\mathrm{Rb}(\Omega)$ & $\begin{array}{l}\text { MRR } \\
\left(\mu \mathrm{m}^{3} / \mathrm{min}\right)\end{array}$ & $\begin{array}{l}\text { TRR } \\
\left(\mu \mathrm{m}^{3} / \mathrm{min}\right)\end{array}$ & $\mathrm{RTW}(\%)$ & $\mathrm{E}(\mu \mathrm{J})$ \\
\hline 5 & $6.2 \times 10^{4}$ & 30 & 0.05 & 4.1 \\
20 & $9.1 \times 10^{4}$ & 24 & 0.03 & 2.1 \\
100 & $9.4 \times 10^{4}$ & $<1$ & $<0.01$ & 0.45 \\
200 & $8.7 \times 10^{4}$ & $<1$ & $<0.01$ & 0.068 \\
500 & $9.0 \times 10^{4}$ & $<1$ & $<0.01$ & 0.029 \\
\hline
\end{tabular}

\subsection{Machining resolution}

Other attempts of machining have been performed successfully with a $\varnothing 3 \mu \mathrm{m}$ microtool without damaging the tool. However, the channel width is not significantly smaller than with the $\varnothing 9 \mu \mathrm{m}$ one. This is attributed to vibrations which induce $+/-5 \mu \mathrm{m}$ oscillations of the apex of the tool tips (as imaged with a slow motion camera at 2000 images/s). Vibrations are present for all tips.

\section{Conclusions}

With the $2^{\text {nd }}$ generation micro EDM milling machine developed in our laboratory, it has been possible to fabricate ultrathin $(\varnothing 9 \mu \mathrm{m})$ high aspect ratio $(\sim 50)$ tungsten microtool and machine stainless steel channels without damaging the microtool.

Different possibilities to improve machining resolution have been explored.

The first one was to reduce the energy per discharge. This has been performed with a ballast resistor. Parts have been successfully machined with $29 \mathrm{~nJ} /$ discharges using a $500 \Omega$ ballast resistor at $50 \mathrm{~V}$ and $1 \mathrm{nF}$ working capacitance. Operating at such a medium range voltage without relying on the machine stray capacitance is an advantage. With a ballast resistor of $100 \Omega$, the relative tool wear was below $0.01 \%$. This is the most significant result of this work since tool wear in $\mu$ EDM milling is known to affect part accuracy so that complex strategies are proposed to overcome this problem [1]. Although no significant result has been shown on the surface characteristics of the channels, future work will evaluate if the reduction of the tool wear allows improving the machining accuracy. However, depending on the value of the ballast resistor $R_{b}$, the channel width is about 31-36 $\mu \mathrm{m}$ with aspect ratio of 1.4-1.8.

The second possibility to improve machining resolution was to use microtools with $3 \mu \mathrm{m}$ diameter. Successful attempts have been performed without damaging the tool. However, no improvement was found in terms of machining resolution. Therefore, the mechanical stability of the machine is currently being improved in order to reduce the tip oscillations.

\section{Acknowledgements}

This work was financed by the FUI ConProMi.

\section{References}

[1] D.T. Pham et al. "Micro-EDM-recent developments and research issues", J. Mat. Proc. Tech., 2004; 149: 50-57.

[2] K. Egashira et al., "Electrical discharge machining of submicron holes using ultrasmall-diameter electrodes", Precision Engineering, 2010; 34: 139-144.

[3] K. Egashira et al., "Electrical discharge machining with ultralow discharge energy", Precision Engineering, 2010; 30: 414-420.

[4] Y. Layouni Y. et al.,"Onboard Electrochemical Fabrication of Microelectrodes for Micro EDM Milling", Micro and Nanosystems, 2011; 3: 215-221.

[5] G. Girardin et al, "Micro EDM with the in situ electrochemical fabrication and regeneration of the tungsten microelectrode tool", Int. J. Mater. Form., 2010; 3: 1083-1086.

[6] G. Girardin, "Développement d'un procédé d'usinage par micro-électroérosion", $\mathrm{PhD}$ thesis, Université de Lyon, Lyon, 2013.

[7] Y. Xia et al.., "Soft Lithography", Angewandte Chemie International Edition, 1998; 37: 550-575. 